\title{
Location of the human posterior eye field with functional magnetic resonance imaging
}

\author{
R M Müri, M T Iba-Zizen, C Derosier, E A Cabanis and C Pierrot-Deseilligny
}

\begin{abstract}
The frontal eye field and parietal eye field are known to be involved during visually guided saccades. As the location of the human parietal eye field is not yet well known, functional MRI was used during such a saccade task to better localise this field. Besides activity in visual areas of the occipital cortex, bilateral activity was seen in the precentral sulcus, corresponding to the frontal eye field, and in the deep region of the intraparietal sulcus. It is suggested that this intraparietal area, bordering areas 39 and 40 of Brodmann, corresponds to the human parietal eye field.
\end{abstract}

(F Neurol Neurosurg Psychiatry 1996;60:445-448)

Keywords: magnetic resonance imaging; posterior eye field; frontal eye field

By contrast with the frontal eye field, little is known about the location of the human posterior eye field. In monkeys, it has been shown that the intraparietal sulcus and the adjacent inferior parietal lobule in the posterior parietal cortex, play an important part in the control of visually guided saccadic eye movements. ${ }^{12}$ Saccades can be elicited by microstimulation of this region, ${ }^{3}$ which has strong projections to the frontal eye field and to the superior colliculus. ${ }^{45}$ In humans, lesions in the parietal cortex result in increased latency and hypometria of contralateral visually guided saccades. ${ }^{67}$ However, the exact location of the parietal region which is responsible for the control of saccadic eye movements is not known, as human parietal lesions often involve rather large areas, and PET studies have not determined this location so far. The recently developed technique of functional MRI (fMRI) has led to a combination of measurements of function related changes in brain activity with high resolution anatomical imaging. Therefore, the aim of our study was to use this technique for a better localisation of the human posterior eye field.

\section{Methods}

SUBJECTS

Nine healthy right handed volunteers (mean age 39 ; range: $29-53$ years), who gave their informed consent were tested. Saccades were elicited by a stimulation ramp of 12 light emitting diodes, placed about $70 \mathrm{~cm}$ from the subject. The subject was instructed to look at the light emitting diodes, which were illuminated successively from right to left and vice versa, and thus made visually guided saccades of $2^{\circ}$ to $5^{\circ}$ (fig $1 \mathrm{~A}$ ). In this paradigm, the direction and timing were predictable, but the amplitude varied in a pseudorandom manner. This paradigm of visually guided saccades, partly predictable, was chosen to reduce the attentional mechanisms involved during more reflexive visually guided saccades. Three subjects were tested using a first procedure with comparison of $\mathrm{fMRI}$ activity obtained during saccades performed for 47 seconds to fMRI activity existing during a resting state of the same duration with the eyes closed. To be sure that such comparative activity was related to saccades and not simply to fixation, two other procedures were used. In the second procedure (with another three subjects), fMRI activity during the fixation of an illuminated central fixation point for 47 seconds was compared with that of a resting state of the same duration with the eyes closed. Finally, in a third procedure (with the remaining three subjects), fMRI activity during saccades was compared with that of fixation (each condition lasting 47 seconds). Although it was not possible to record eye movements during fMRI, it may reasonably be assumed that these simple ocular motor tasks were correctly performed by normal subjects during fMRI, as, under laboratory conditions with eye movement control, normal subjects perform such tasks without any difficulty.

\section{MRI}

MRI was performed using a 1.5 Tesla MR (Signa Advantage, V. 5x, General Electric Medical Systems). Before fMRI, a whole brain fast spoiled grass inversion recovery (FSPGRIR) preparation $3 D$ in the sagittal plane (124 slices, $1 \mathrm{~mm}$ thick) was made for each subject, using a head coil. The fMRI was performed with a set of two 3 inch coils centred on the posterior parietal region: four to six contiguous planes parallel to the middle part of the corpus callosum were studied in each subject. The lowest plane was set at the junction of the posterior parietal and occipital fis- 
(A) Electro-oculography (outside the $M R$ ) of visually guided saccades elicited by the same stimulus screen as used during fMRI. (B) Axial image at the level of the intraparietal sulcus during the first procedure (saccades versus rest). Voxels with a crosscorrelation of more than $66 \%$ and a signal change of more than $2.3 \%$ are presented as white spots. The curve in the upper part of the figure shows the time course of the

functional MRI activity of the corresponding voxels. (C) Results of functional $M R I$ are transferred to the individual inversion recovery images, showing activity in both

intraparietal sulci, and in the right frontal eye field. Activity in the left frontal eye field was observed in this subject in the functional MRI slice immediately above. (D)

Schematic representation of the activity zones in the three examined subjects during the saccade versus rest procedure on a

horizontal section passing through the upper part of the cerebral hemispheres: in all subjects, bilateral activity was observed in the deep region of the intraparietal sulcus (bordering area 39 and/or 40 of Brodmann) and in the frontal eye field. $c s=$ central sulcus; ip $=$ intraparietal sulcus; $p c s=$ precentral sulcus; in $B, C$, and $D$ the right side is on left.

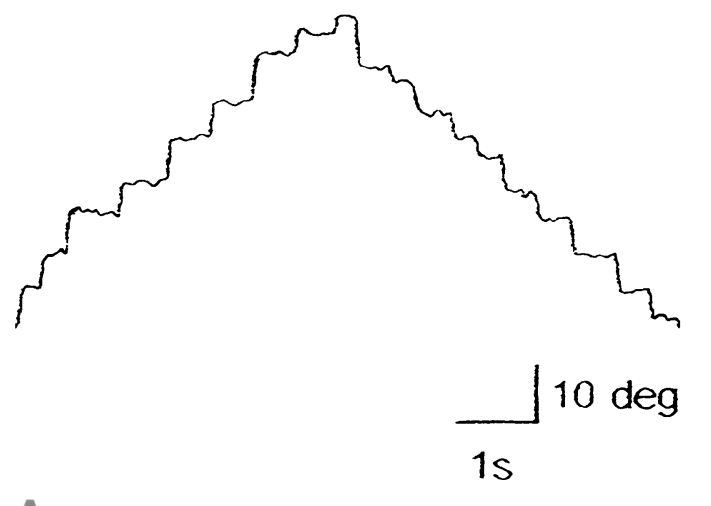

A

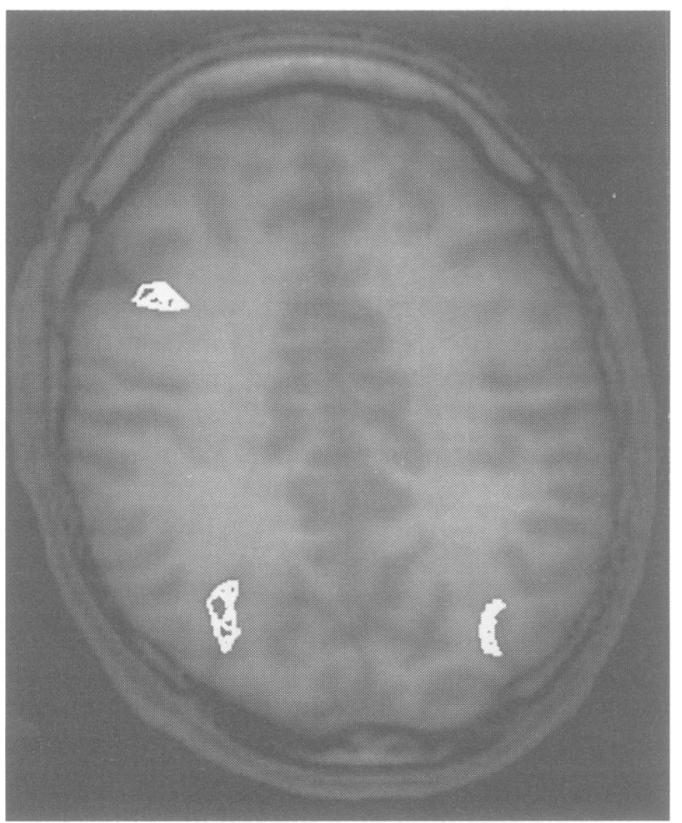

C

sures. A spoiled grass (SPGR) sequence (TE: $60 \mathrm{~ms}$, TR: $70 \mathrm{~ms}$, flip angle: $40^{\circ}$; matrix; 256, 35 slices per plane, $5 \mathrm{~mm}$ thick, field of view (FOV): $320 \mathrm{~mm}$ resulting in a voxel of $6.25 \mathrm{~mm}^{3}$ ) was used with an interplane space, varying from 5 to $10 \mathrm{~mm}$, to include the occipital cortex and the superior frontal and parietal cortex. For each plane, alternating series of five slices with and without activity were studied. For further analysis, data were transferred to an Advantage Windows Work Station, and the fMRI series were processed with customised software. ${ }^{8}$ The region of interest included the whole brain. The signal was fitted by linear regression and a cross correlation of the temporal signal (activity versus rest) was

Brain activity on $f M R I$ during the various procedures

\begin{tabular}{|c|c|c|c|c|c|c|}
\hline \multirow[b]{2}{*}{ Activated area } & \multicolumn{2}{|c|}{$\begin{array}{l}\text { Saccades } \\
v \text { rest }\end{array}$} & \multicolumn{2}{|c|}{$\begin{array}{l}\text { Fixation } \\
v \text { rest }\end{array}$} & \multicolumn{2}{|c|}{$\begin{array}{l}\text { Saccades } \\
v \text { fixation }\end{array}$} \\
\hline & right & left & right & left & right & left \\
\hline FEF (area 8) & + & + & - & - & + & + \\
\hline Intraparietal sulcus & + & + & - & - & + & + \\
\hline $\begin{array}{l}\text { Calcarine sulcus } \\
\text { (area 17) }\end{array}$ & + & + & + & + & $(+)$ & $(+)$ \\
\hline $\begin{array}{l}\text { Dorsal occipital cortex } \\
\quad(\text { area } 18 \text { and 19) }\end{array}$ & + & + & + & + & $(+)$ & $(+)$ \\
\hline
\end{tabular}

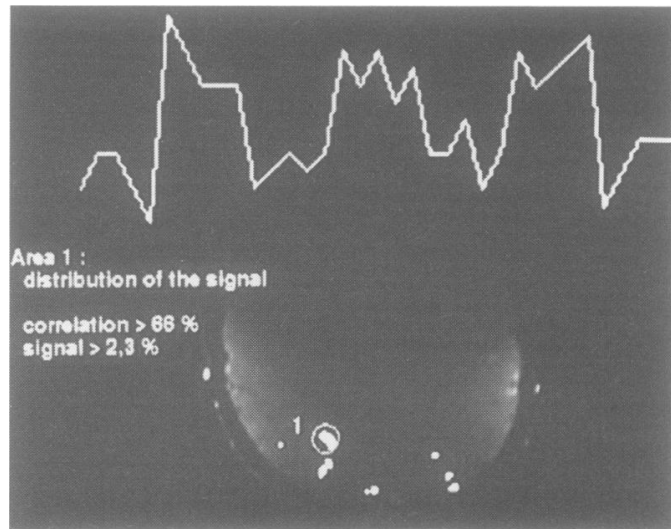

B

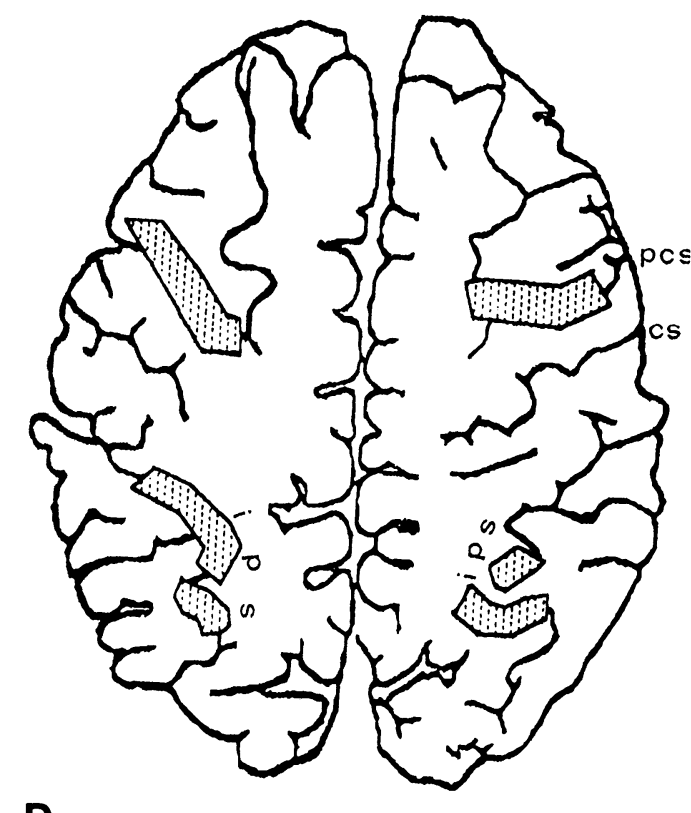

D

performed. ${ }^{9}$ Only voxels with a cross correlation superior to $66 \%$ and a signal superior to $2.3 \%$ were retained for final analysis (fig $1 \mathrm{~B}$ ), and matched with the slice of the corresponding plane. Finally, the results were fused to the individual 3D MRI reformatted brain (fig 1C) with Advantage Windows Voxtool software.

\section{Results}

Activity in the PPC region was determined in respect to the important landmark formed by the intraparietal sulcus. According to Duvernoy, ${ }^{10}$ the intraparietal sulcus, which divides the parietal lobe into the superior and inferior parietal lobules, consists of three parts: (1) an anterior ascendant part, identical to the inferior part of the postcentral sulcus; (2) a middle horizontal part, which is the intraparietal sulcus in the strict sense; and (3) a posterior descending part lying in the occipital lobe.

In the saccade versus rest procedure, significant activity in the region of both frontal eye fields, around the precentral sulcus, was seen in all three subjects (fig 1D). Furthermore, activity in the horizontal part of the intraparietal sulcus which was located deep in the sul- 
cus, existed near the limit between the angular gyrus and supramarginal gyrus (areas 39 and 40 of Brodmann). In general, activity seemed to be more pronounced on the right than on the left side, but a quantification of asymmetry was not performed. Activity in the primary visual cortex and in the region of the dorsal occipital cortex was also noted in all subjects (table). During the fixation versus rest procedure, no activity was noted either in the frontal eye field or in the horizontal part of the intraparietal sulcus. However, in all three subjects, there was bilateral activity in the primary visual cortex and the dorsal occipital cortex. Finally, in the third procedure (saccades versus fixation), activity was observed in two of the three subjects in both frontal eye fields, and activity in the horizontal part of the intraparietal sulcus was found in all subjects. By contrast the activity in the primary visual cortex and the dorsal occipital cortex was very weak in this procedure.

\section{Discussion}

The technique of fMRI can be used for mapping visual and motor functions. ${ }^{11-16}$ There are only a few reports concerning eye movement related activity using $\mathrm{fMRI},{ }^{17}{ }^{18}$ and the location of the parietal eye field has not yet been studied in detail. The results of our first procedure (saccades versus rest) confirm the localisation of the frontal eye field around the precentral sulcus, at the level of the middle frontal gyrus, and activity was observed on both the right and left side. It is now established that visually guided saccades are controlled by both the frontal eye field and parietal eye field in the monkey ${ }^{1920}$ as in humans. ${ }^{621}$ In our study, activity of the frontal eye field can, therefore, be taken as confirmation that subjects performed saccades, as assumed, during the saccade task.

The results of our first procedure also suggest that the human parietal eye field is located in the intraparietal sulcus. The bilateral activity observed in this sulcus seemed to be saccade specific and not simply due to visual activity, as, in the second procedure, visual fixation did not activate this region, but did activate striate and extrastriate visual cortical areas, as in the first procedure. Furthermore, in the third procedure (saccades versus fixation), the same frontal and parietal areas as in the first procedure were active (the frontal eye field and the intraparietal sulcus), whereas the activity of occipital visual areas was not significant in this visual (moving target) versus visual (fixation) comparison.

For several reasons, it is also likely that activity of the intraparietal sulcus may not be attributed only to visual attention effects. Although attention and saccade programming are usually linked, ${ }^{22}$ we tried in the saccadic stimulation to reduce the attentional demand by using partly predictable visual targets. Furthermore, the superior posterior parietal cortex, which is important for visual attention, ${ }^{23}$ and could be responsible for shifting attention from one stimulus to the next, was not significantly active in our study. Lastly, it is conceivable that saccades and fixation (third procedure) require similar visual attentional demands. It should be noted that long attentive fixation is not a passive rest state of the eyes, but requires an active will to hold fixation $^{24}$ and most of the subjects found this state more difficult to perform than the saccade task. Despite the assumed subtraction of attentional demand in this third procedure (saccades versus fixation), an activity in the intraparietal sulcus comparable with that of the saccade versus rest was noted. This suggests that such activity was largely saccade related. Finally, our results are consistent with experimental findings in monkeys showing that the parietal eye field is located in the intraparietal sulcus, ${ }^{12}$ and the results of clinical lesion studies, which suggested that the equivalent area in humans is located in the intraparietal sulcus region. ${ }^{25} 6$ Furthermore, our results suggest that the parietal eye field lies $(a)$ in the deep region of the intraparietal sulcus and $(b)$ in the horizontal part of this sulcus-that is, at the level of areas 39 and 40 of Brodmann.

In conclusion, our study is the first, to our knowledge, confirming the location of the human parietal eye field in the intraparietal sulcus using fMRI. More studies are needed to determine in detail the parietal eye field location within the intraparietal sulcus, in particular in respect to the lateral and medial banks of the fundus of this sulcus.

1 Barash S, Bracewell RM, Fogassi L, Gnadt JW, Andersen RA. Saccade-related activity in the lateral intraparietal area. I. Temporal properties; comparison with area 7 a. $\mathcal{F}$ Neurophysiol 1991;66:1095-108.

2 Barash S, Bracewell RM, Fogassi L, Gnadt JW, Andersen RA. Saccade-related activity in the lateral intraparietal area. II. Spatial properties. I Neurophysiol 1991;66: 1109-24.

3 Shibutani H, Sakata H, Hyvarinen J. Saccade and blinking evoked by microstimulation of the posterior parietal asso-
ciation cortex of the monkey. Exp Brain Res 1984;55:1-8.

4 Barbas H, Mesulam MM. Organization of afferent input to subdivisions of area 8 in the rhesus monkey. $f$ Comp subdivisions of area 8 in

5 Lynch JC, Graybiel AM, Lobeck LJ. The differential projection of two cytoarchitectonic subregions of the inferio parietal lobule of macaque upon the deep layers of the superior colliculus. F Comp Neurol 1985;235:241-54

6 Pierrot-Deseilligny C, Rivaud S, Gaymard B, Agid Y. Cortical control of reflexive visually-guided saccades. Brain 1991;114:1473-85.

7 Pierrot-Deseilligny C, Rivaud S, Penet C, Rigolet MH Latencies of visually-guided saccades in unilateral hemispheric cerebral lesions. Ann Neurol 1987;21:138-48.

8 Derosier C, Caritu Y, Cordolani YS, Cosnard G. Une technique de traitement du signal en IRM pour l'imagerie fonctionelle. F Radiol (Paris) 1994;75:515-8.

9 Bandettini PA, Jesmanowicz A, Wong EC, Hyde JS Processing strategies for functional MRI of the human Processing strategies for functional Mr. Magn Reson Med 1993;30:161-73.

10 Duvernoy H. The human brain. Surface, three-dimensional sectional anatomy and MRI. New York: Springer, 1991.

11 Blamire AM, Ogawa S, Ugurbil K, et al. Dynamic mapping of the human visual cortex by high-speed magnetic resonance imaging. Proc Natl Acad Sci USA 1992;89. 11069-73.

12 Kwong KK, Belliveau JW, Chesler DA, et al. Dynamic magnetic resonance imaging of human brain activity during primary sensory stimulation. Proc Natl Acad Sci USA 1992;89:5675-9.

13 Rao SM, Binder JR, Bandettini PA, et al. Functional magnetic resonance imaging of complex human movements. Neurology 1993;43:2311-8.

14 Boecker $\mathrm{H}$, Kleinschmidt A, Requardt $\mathrm{M}$, et al. Functional cooperativity of human cortical motor areas during selfcooperativity of human cortical motor areas during selfpaced simple finger movements.
study. Brain 1994;117:1231-9.

15 Turner R. Magnetic resonance imaging of brain function. Ann Neurol 1994;35:637-8.

16 Cabanis EA, Iba-Zizen MT, Wu BS, et al. Functional magnetic resonance imaging of visual cortex: methodological considerations. Neuroradiology 1994;36:45. 
17 Darby DG, Nobre AC, Thangaraj V, et al. Cortical activation during self- and stimulus-guided saccadic lateral eye movements in the human brain, using EPISTAR functional MRI. Soc Neurosci Abstr 1994;20:434

18 Kleinschmidt A, Merboldt K-D, Requardt M, Hänicke W, Frahm J. Functional MRI of cooperative cortical activaFrahm J. Functional MR of cooperative cortical activation patterns

19 Lynch JC. The functional organization of posterior parietal association cortex. Behav Brain Sci 1980;3:485-534

20 Bruce CJ, Goldberg ME. Primate frontal eye fields: I Single neurons discharging before saccades. $f$ Neurophysiol 1985;53:603-35.

21 Rivaud S, Müri RM, Gaymard B, Vermersch AI, Pierrot-
Deseilligny C. Eye movement disorders after frontal eye field lesions in humans. Exp Brain Res 1994;102:110-20. 22 Kowler E, Anderson E, Dosher B, Blaser E. The role of attention in the programming of saccades. Vis Res 1995;35:1897-916.

23 Corbetta M, Miezin FM, Shulman GL, Petersen SE. A PET study of visuospatial attention. F Neurosci 1993; 13:1202-26.

24 Anderson TJ, Jenkins IH, Brooks DJ, et al. Cortical control of saccades and fixation in man. A PET study. Brain 1994;117:1073-84.

25 Pierrot-Deseilligny C, Rivaud S, Gaymard B, Agid Y. Cortical control of memory-guided saccades in man. Exp Brain Res 1991;83:607-17.

\section{Migraine}

\section{Continued from this fournal 1996;60:338.}

$S$ Cervantes, 1547-1616, Don Quixote $(1605,1615)$ When the head aches, all the limbs partake of the pains.

William Shakespeare, 1564-1616, Romeo and Juliet (1595)

Lord, how my head aches. What a head have I! It beats as it would fall in twenty pieces.

Paulus Aeginete, sixth century

... a permanent pain of the head, liable to be increased by noises, cries, a brilliant light, drinking of wine or strong smelling things which fill the head.

Lord Chesterfield, 1694-1773, Letters to my son (1749). Those who see and observe things, heroes and statesmen, discover that they have headaches, indigestion, humours and passions, just like other people.

Christopher Hibbert, 1924, The making of Charles Dickens (1967)

Once again as before his marriage, overwork had a deleterious effect on his health. Towards the end of the previous year he had been suffering from "the torment of rheumatism in the face" and intermittent headaches of such violence that he was sometimes-so he told Bentley-wholly disabled from putting pen to paper and he was prescribed as much medicine as would confine an ordinary-sized horse to his stall for a week.

Arthur Ransome, 1884-1967, The autobiography (1976)

I was troubled at that time with violent headaches, for which I found walking the best though a painful cure. I used to set out from my studio half blind with pain and, stumbling resolutely on, would find the pain lessening and at last gone altogether. One day with one of these headaches I set out from the Rue Campagne Permière and walked out by the Lion de Belfort to the fortifications, when, though I found my headache slackening, the fine spring evening made me unwillingly turn back.

Fames Pope Hennessey, Anthony Trollope. About Anthony Trollope's bankrupt father:

In after years Mr Trollope's surviving children agreed amongst themselves that their father's brain and physique had become deranged through excessive use of calomel, which causes severe mercury poisoning. All his life he had been subject to violent migraines, for which calomel in appropriate doses was then believed to bring relief. But instead of small, regular doses, $\mathrm{Mr}$ Trollope took to calomel with the blind zeal of a modern heroin addict. He became more and more excitable, making scenes with his sons about money; and to everyone who came his way he would behave as unpleasantly as only he knew how to do. As prime victim for his rage he would especially pick upon his second son, Henry, who was indolent and apathetic but who was probably already riddled by consumption. During such scenes Henry would appeal to his mother for help. After them, Mrs Trollope, like many of her contemporaries would take laudanum in order to sleep.
It is probable that Mr Crawley, the austere and penniless clergyman in Framley Parsonage, who suffers from pride and melancholia and who is forever drilling Latin into his children, may have been suggested to Anthony Trollope by his father's stern character and gloomy pursuits.

Mary Stewart 1916- , Wildfire at Midnight (1956) It was precisely at one forty eight am. The tiny illuminated face of my travelling clock stared uncompromisingly back at me from the bedside table. I scowled at the clock again, then slipped out of bed. I was jaded and depressed, and I knew that I had already reached the stage when my failure to sleep was so actively irritating that sleep had become an impossibility. What was worse, I knew I was in for one of the blinding nervous headaches that had devastated me all too often in the last 3 or 4 years. I could feel the warning now, like a tiny electric wire thrilling behind my eyes; pain, with the elusive threat of worse pain to come.

I sat on the edge of the bed, pressing my hands hard against my eyes, trying to will the pain away, while still, in my wincing brain, whirled and jostled the images that, conspiring to keep sleep at bay, had switched the agonizing current along my nerves.

I shivered, then flinched and stood up. I wasn't even going to try and ride this one out; I was going to dope myself out of it, and quickly. The life-saving tablets were in my handbag. I paddled across the room to get it, groping vaguely among the grotesque shadows that distorted the corners of the room. But it wasn't on the dressing table. It wasn't on the mantelpiece. Or on the floor near the handbasins. Or by the bed. Or-it was by now a search of despair-under the bed. It wasn't anywhere in the room.

I sat down on the bed again, and made myself acknowledge the truth. I hadn't taken my handbag on that walk. I had left it in the lounge. I could see it in my mind's eye, standing there on the floor beside my chair, holding that precious pill-box, as remote from me as if it had been on a raft in the middle of the Red Sea. Because ... nothing, I told myself firmly, wincing from a fresh jag of pain, nothing was going to get me out of that room that night. If anyone was to perform the classic folly of taking a midnight stroll among the murderous gentlemen with whom the hotel was packed, it was not going to be me. On this eminently sensible note I got back into bed, blew out the candle, and settled down to ride it out.

Seventeen minutes later I sat up, lit the candle again, got out of bed and grabbed my housecoat. I had reached in 17 minutes of erratically increasing pain, an even more sensible decision-and how much this was a product of reason and how much of desperation I can now judge more accurately than I could then. It was quite a simple decision, and very satisfactory. I had decided that James Farlane had murdered Heather Macrae. And since Jamesy Farlane didn't live in the hotel, I could go and get my tablets with perfect safety.

Perfect safety, I told myself firmly, thrusting my feet into my slippers and knotting the girdle of my housecoat tightly round me-as long as I was very quick, and very quiet, and was prepared to scream like blazes if I saw or heard the least little thing. 